7. Reprod. Fert. (1966) 11, 313-316

BRIEF COMMUNICATION

\title{
INFLUENCE OF PREGNANT PARABIOTIC PARTNERS ON TIME OF PARTURITION IN RATS
}

\author{
SERGE J. MANTALENAKIS* AND MELVIN M. KETCHEL* \\ Worcester Foundation for Experimental Biology, Shrewsbury, Massachusetts
}

(Received 16th December 1965)

Although considerable information is accumulating concerning the endocrinology of parturition, the nature of the underlying stimulus controlling the onset of parturition remains obscure (for review see Marshall \& Moir, 1952; Zarrow, 1961). The present study was undertaken to determine whether or not parabiosis would reveal the existence of a humoral factor which controls the onset of parturition. Earlier studies by Sauerbruch \& Heyde (1910), Fels (1929) and Hill (1932) demonstrated that parturition is unaffected in a pregnant rat joined in parabiosis with a non-pregnant rat. Kross (1926) and Munemitsu \& Segal (1959) reported no evidence of a disturbance in length of gestation or in parturition when two pregnant rats were placed in parabiosis. We reasoned that a humoral factor released as a stimulus to parturition in the rat might not cause the onset of parturition in its parabiotic partner unless the partner was near term. We therefore prepared a series of rats in parabiosis in which the two members of each pair were either $4,3,2,1$ or 0 days apart in the time at which mating occurred.

Adult female Sprague-Dawley rats weighing 180 to $240 \mathrm{~g}$ were placed in mating cages in the evening with normal males to obtain pregnant females, or with vasectomized males to obtain pseudopregnant females. Pregnancy or pseudopregnancy was inferred by the presence of a vaginal plug early the following day, which was designated Day 1. In each parabiotic pair a rat on Day $14,15,16$ or 17 of pregnancy was placed on the left. The rat on the right had mated either 4, 3, 2, 1 or 0 days later, or was on Day 2 or 3 of pseudopregnancy. The method of parabiosis was that of Bunster \& Meyer (1933), modified by the establishment of a permanent coelioanastomosis. Near the time of parturition the rats were observed at 2-hr intervals to record the time of parturition and to remove the young. Statistical tests utilized the Signed Rank Test of Wilcoxon \& Wilcox (1964).

There was no evidence in any group that parturition of the first rat to deliver influenced the time of onset of parturition in the second rat (Table 1). However, in Groups II and III ( 3 and 2 days apart, respectively) there was a significant delay in the time of onset of parturition in the first rat of the pair to deliver. In Group $\mathrm{V}$, in which both members of each pair became pregnant on the same day, we did not observe any instances in which both members of a pair

* Present address: Tufts University School of Medicine, Boston, Massachusetts. 


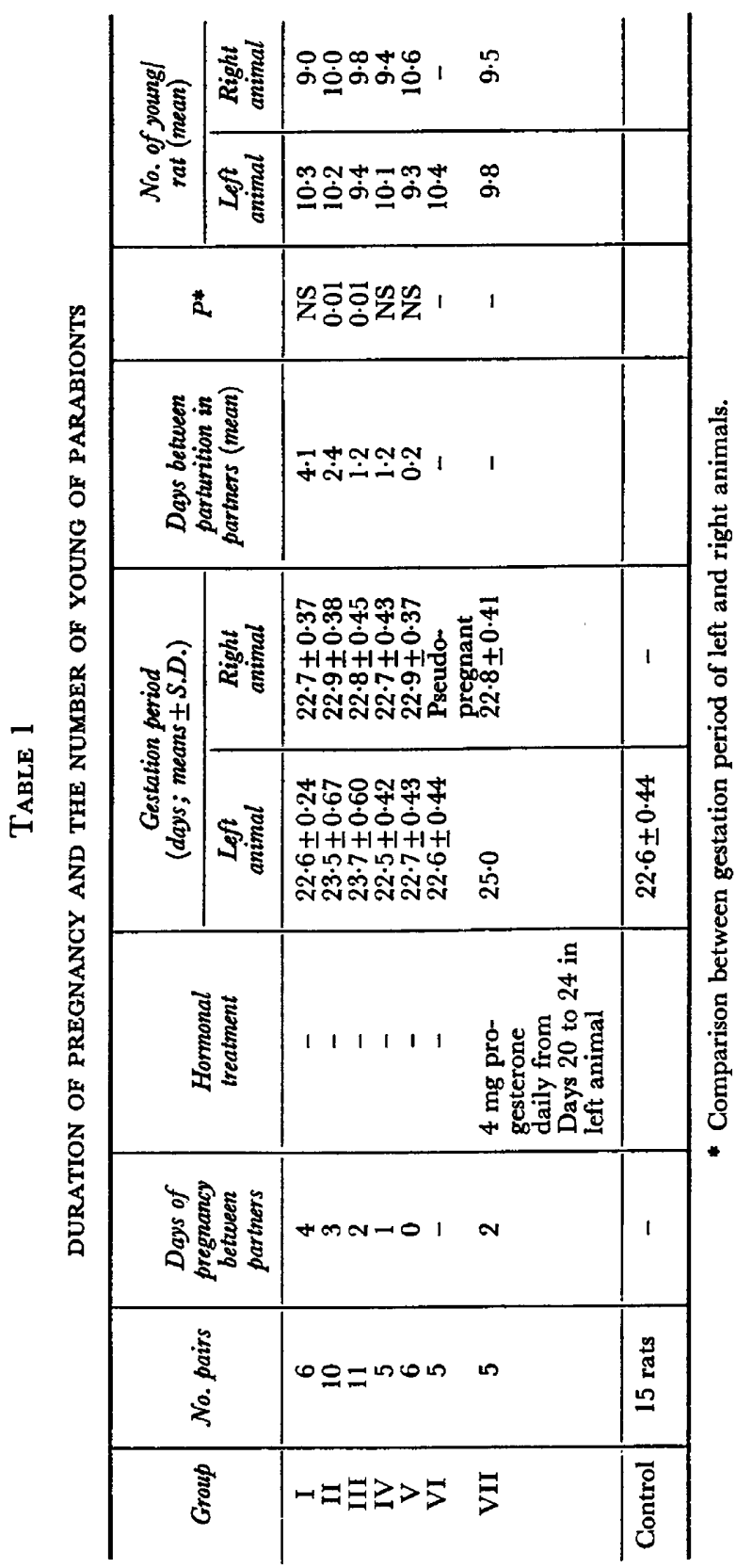


were giving birth at the same time, and the times between their parturition ranged from 1 to $18 \mathrm{hr}$.

Group VI consists of pairs of parabiotic rats in which the left member of each pair was on Day 15 or 16 of pregnancy and the right member was on Day 2 or 3 of pseudopregnancy. Parturition in the pregnant rats was unaffected by parabiosis with the pseudopregnant partner.

Group VII consists of pairs of parabiotic rats in which the left member of each pair became pregnant 2 days earlier than the right member. On Days 20 to 24 of its pregnancy the left rat was injected daily with $4 \mathrm{mg}$ of progesterone to delay parturition. Parturition in the uninjected member of each pair occurred at the normal time, which coincided with Day 24 of the pregnancy of the injected rat. There was no indication that progesterone inhibition of the parturition of one rat affected the onset of parturition in its parabiotic partner.

In the design of the present experiments it was assumed that if a humoral factor causing the onset of parturition existed, it would be noted when it crossed from the rat undergoing parturition to its parabiotic partner and influenced the time of parturition. Although Alloiteau (1963) has reported an apparent exception, it appears that protein hormones do pass readily between rats in parabiosis (for review, see Finerty, 1952). On the other hand, the work of Fels (1940), Biddulph, Meyer \& Gumbreck (1940), Porto (1943) and Huff, Trautman \& Van Dyke (1950) indicates that steroid hormones cross from one parabiotic rat to its partner only when the hormone concentration reaches very high levels. Presumably at physiological levels the steroids disappear from the circulation before significant crossing occurs. Therefore, while the present experiments show no evidence of a humoral factor causing the onset of parturition, they do not rule out the possibility that such a factor exists.

Schofield (1957) showed that the rabbit's uterus does not acquire its reactivity to oxytocin until the last 2 or 3 days of gestation. We expected that oxytocin from the blood of the first rat to initiate parturition would cause the initiation of parturition of the second rat in those pairs in which the two rats became pregnant at close to the same time. Since this did not occur, we think it is likely that oxytocin from the rat undergoing parturition did not attain a significant concentration in the blood of its parabiotic partner.

The delay in parturition observed in rats in parabiosis with rats which became pregnant 2 or 3 days later strongly suggests that a factor inhibiting parturition is in high concentration on Days 20 and 21 of pregnancy, and is able to cross between rats in parabiosis.

Work supported in part by Grant HD-00055-02 from the National Institute of Child Health and Human Development, Department of Health, Education, and Welfare, and in part by a grant from the Population Council. The authors wish to express their appreciation to Miss Ellen Babas for valuable technical assistance.

\section{REFERENCES}

Alloiteau, J. J. (1963) Comportement des luteotropines hypophysaire et placentaire chez des rattes hypophysectomisées en parabiose. C.r. Séanc. Acad. Sci., Paris, 256, 277.

Biddulph, G., Meyer, R. K. \& Gumbreck, L. G. (1940) The influence of estriol, estradiol and progesterone on the secretion of gonadotropic hormones in parabiotic rats. Endocrinology, 26, 280. 
Bunster, E. \& Meyer, R. K. (1933) An improved method of parabiosis. Anat. Rec. 57, 339.

FELs, E. (1929) Experimentelle Studien an Parabiose-Tieren über Physiologie und Biologie der Sexualhormone. Arch. Gynaek. 138, 16.

FeLs, E. (1940) Investigaciones experimenteles sobre el inter cambio de las hormonas sexuales en la parabiosis. Anal. Fac. Med. Univ. Montevideo, Special Issue, 142.

Finerty, J. C. (1952) Parabiosis in physiological studies. Physiol. Rev. 32, 277.

HiLl, R. T. (1932) The blood exchange and hormonic reaction in parabiotic rats. F. exp. Zool. 63, 203.

Huff, R. L., Trautman, R. \& Van Dyke, D. C. (1950) Nature of exchange in parabiotic rats. Am. $\mathcal{F}$. Physiol. 161, 56.

Kross, I. (1926) An investigation into the causation of the onset of labor by parabiosis during pregnancy. Am. 7. Obstet. Gynec. 11, 64.

Marshald, F. H. A. \& Motr, J. C. (1952) Parturition. Marshall's Physiology of Reproduction, 3rd edn, vol. 2, p. 496. Ed. A. S. Parkes. Longmans Green, London.

Munemitsu, S. \& Segal, S. J. (1959) Endocrine role of rat placenta as revealed by experiments in parabiosis. Archs Anat. microsc. Morph. exp. Paris, 48, 173.

Porto, A. (1943) A pasgens de substancias androgenicus nas parabiosis de ratos castrados con ratos normais. Mems Inst. Butantan, 17, 83.

SAUERbRUch, F. \& Heyde (1910) Untersuchangen über die Ursachen des Geburtseintritten. Münch. med. Wschzr. 57, 2617.

Schofield, B. M. (1957) The hormonal control of myometrial function during pregnancy. F. Physiol., Lond. 138, 1.

Wilcoxon, F. (1945) Individual comparisons by ranking methods. Biometrics, 1, 80.

ZARrow, M. X. (1961) Gestation, sex and internal secretions, 3rd edn, vol. 2, p. 958. Ed. W. G. Young. Williams \& Wilkins, Baltimore. 